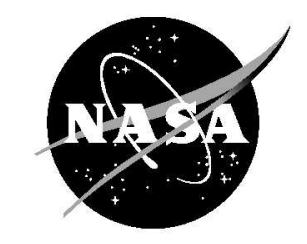

\title{
Design and Implementation of a Characterization Test Rig for Evaluating High Bandwidth Liquid Fuel Flow Modulators
}

Joseph R. Saus, Clarence T. Chang, John C. DeLaat, and Daniel R. Vrnak Glenn Research Center, Cleveland, Ohio 


\section{NASA STI Program . . . in Profile}

Since its founding, NASA has been dedicated to the advancement of aeronautics and space science. The NASA Scientific and Technical Information (STI) program plays a key part in helping NASA maintain this important role.

The NASA STI Program operates under the auspices of the Agency Chief Information Officer. It collects, organizes, provides for archiving, and disseminates NASA's STI. The NASA STI program provides access to the NASA Aeronautics and Space Database and its public interface, the NASA Technical Reports Server, thus providing one of the largest collections of aeronautical and space science STI in the world. Results are published in both non-NASA channels and by NASA in the NASA STI Report Series, which includes the following report types:

- TECHNICAL PUBLICATION. Reports of completed research or a major significant phase of research that present the results of NASA programs and include extensive data or theoretical analysis. Includes compilations of significant scientific and technical data and information deemed to be of continuing reference value. NASA counterpart of peer-reviewed formal professional papers but has less stringent limitations on manuscript length and extent of graphic presentations.

- TECHNICAL MEMORANDUM. Scientific and technical findings that are preliminary or of specialized interest, e.g., quick release reports, working papers, and bibliographies that contain minimal annotation. Does not contain extensive analysis.

- CONTRACTOR REPORT. Scientific and technical findings by NASA-sponsored contractors and grantees.
- CONFERENCE PUBLICATION. Collected papers from scientific and technical conferences, symposia, seminars, or other meetings sponsored or cosponsored by NASA.

- SPECIAL PUBLICATION. Scientific, technical, or historical information from NASA programs, projects, and missions, often concerned with subjects having substantial public interest.

- TECHNICAL TRANSLATION. Englishlanguage translations of foreign scientific and technical material pertinent to NASA's mission.

Specialized services also include creating custom thesauri, building customized databases, organizing and publishing research results.

For more information about the NASA STI program, see the following:

- Access the NASA STI program home page at http://www.sti.nasa.gov

- E-mail your question via the Internet to help@ sti.nasa.gov

- Fax your question to the NASA STI Help Desk at $443-757-5803$

- Telephone the NASA STI Help Desk at 443-757-5802

- Write to: NASA Center for AeroSpace Information (CASI) 7115 Standard Drive Hanover, MD 21076-1320 
NASA/TM-2010-216105

AIAA-2009-4886

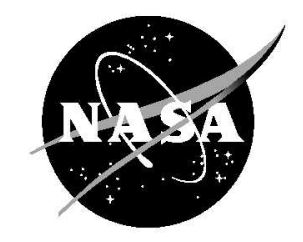

\section{Design and Implementation of a Characterization Test Rig for Evaluating High Bandwidth Liquid Fuel Flow Modulators}

Joseph R. Saus, Clarence T. Chang, John C. DeLaat, and Daniel R. Vrnak Glenn Research Center, Cleveland, Ohio

Prepared for the

45th Joint Propulsion Conference and Exhibit cosponsored by AIAA, ASME, SAE, and ASEE

Denver, Colorado, August 2-5, 2009

National Aeronautics and

Space Administration

Glenn Research Center Cleveland, Ohio 44135 
Trade names and trademarks are used in this report for identification only. Their usage does not constitute an official endorsement, either expressed or implied, by the National Aeronautics and Space Administration.

This work was sponsored by the Fundamental Aeronautics Program at the NASA Glenn Research Center.

Level of Review: This material has been technically reviewed by technical management.

Available from

NASA Center for Aerospace Information 7115 Standard Drive

Hanover, MD 21076-1320
National Technical Information Service 5301 Shawnee Road Alexandria, VA 22312

Available electronically at http://gltrs.grc.nasa.gov 


\title{
Design and Implementation of a Characterization Test Rig for Evaluating High Bandwidth Liquid Fuel Flow Modulators
}

\author{
Joseph R. Saus, Clarence T. Chang, John C. DeLaat, and Daniel R. Vrnak \\ National Aeronautics and Space Administration \\ Glenn Research Center \\ Cleveland, Ohio 44135
}

\begin{abstract}
A test rig was designed and developed at the NASA Glenn Research Center (GRC) for the purpose of characterizing high bandwidth liquid fuel flow modulator candidates to determine their suitability for combustion instability control research. The test rig is capable of testing flow modulators at up to $600 \mathrm{psia}$ supply pressure and flows of up to $2 \mathrm{gpm}$. The rig is designed to provide a quiescent flow into the test section in order to isolate the dynamic flow modulations produced by the test article. Both the fuel injector orifice downstream of the test article and the combustor are emulated. The effect of fuel delivery line lengths on modulator dynamic performance can be observed and modified to replicate actual fuel delivery systems. For simplicity, water is currently used as the working fluid, although future plans are to use jet fuel. The rig is instrumented for dynamic pressures and flows and a high-speed data system is used for dynamic data acquisition. Preliminary results have been obtained for one candidate flow modulator.
\end{abstract}

\section{Introduction}

In response to increasingly strict limitations on emission output levels for both land-based and aircraft gas turbine engines, combustion research has focused on leaner-burning combustion concepts. However, these leaner-burning concepts have shown an increased susceptibility to combustion instabilities (Refs. 1 to 5). These instabilities can cause combustor pressure oscillations which, left unchecked, lead to increased vibration levels and potentially premature mechanical failure. One of the mechanisms that have been identified as contributing to these instabilities is the coupling of the combustion heat release with the inherent combustor geometry acoustics (thermo-acoustic instabilities). Ideally, passive techniques would be the most attractive solution to solve these problems because they minimize weight and component count. However, given the range of conditions over the complete mission cycle of the engine, a passive technique may not be fully successful. For this reason, it is prudent to also investigate techniques for active control (Refs. 5 to 17).

Active Combustion Instability Control addresses the instability mechanism previously mentioned. The basic approach is to modulate fuel into the combustor so as to decouple the combustion heat release process from geometry-induced acoustic frequencies that produce instabilities. If performed correctly (i.e., supplying appropriate magnitude and phase in the modulated fuel output), the result of the control action attenuates the amplitude of the instability.

The success of providing active control, then, hinges largely upon having a fuel actuator with adequate bandwidth and modulation strength to cover the frequency range over which instabilities have been observed. In the body of research to date, combustion instabilities in gas turbine engines have generally been observed in the 100 to $1000 \mathrm{~Hz}$ range (military engines have encountered some even higher). Unfortunately, actuators with this type of bandwidth are not available as off-the-shelf manufactured items. Therefore, it has become necessary to develop custom fuel actuators which satisfy these requirements.

In order to ensure that the performance of a given candidate fuel modulator is suitable for use in an active control application; it becomes necessary to perform dynamic characterization testing. It is for this reason that a characterization test rig was designed and developed at the NASA Glenn Research Center. 
This paper begins with a description of the overall construction of the fuel modulator characterization test rig. Details are provided for some of its unique components that approximate the hardware and cold flow conditions of a combustion research rig (i.e., fuel injection and backpressure). The rig instrumentation is then described along with the type of data collected from a test candidate and the procedures employed for its collection. Next, an example fuel modulator is described. Representative data is presented for the tested candidate along with the conclusions drawn on its performance. Finally, future plans for the rig are given.

\section{Overall Rig Construction}

As a preface to describing the rig's construction, it is prudent to mention the underlying rationale that determined the design guidelines. In general terms, the form and function of the rig stemmed from the need to accurately assess the performance of a candidate modulation device when subjected to conditions it would experience when connected to a combustion rig. These conditions would include input and exit pressures, mass flows, and flow resistances. In addition, it should be noted that for safe operation, all components are designed in accordance with ASME standards where applicable.

In the planning stage for NASA's first attempts to demonstrate active combustion instability control, the main fuel supply of the combustor was selected as the source media for effecting the control. The rationale for making this choice was the belief that the main fuel injection offered the maximum available potential for influencing the combustion process and therefore presented the best chance for achieving a successful demonstration. In making this decision, an upper bound had been specified for the characterization rig's flow capacity. In particular, NASA Glenn had down-selected a fuel injector for supplying fuel into a single nozzle combustion rig that had a Flow Number rating of 110 associated with its main fuel flow. Flow Number for an orifice is defined as:

$$
\text { Flow Number }=\frac{\dot{m}}{\sqrt{\Delta P}}
$$

with $\dot{m}$ being the fluid mass flow in $\mathrm{lbm} / \mathrm{hr}$ (abbreviated pph) and $\Delta P$ being the pressure differential in psi across the orifice, such that the resulting units for Flow number are (pph-psi ${ }^{-0.5}$ ). The maximum working pressure for the rig was specified to be $600 \mathrm{psig}$. This decision was based on the known maximum fuel supply pressure present in the combustion facility where the Active Combustion Control research was to be performed. Table I shows the test conditions for that research. Given the specified Flow Number across the fuel injection orifice and knowing a desired mass flow rate for a defined flow condition, it is possible to determine the required differential pressure across that orifice using Equation (1). Knowing the corresponding combustion pressure for that flow condition one can then calculate the differential pressure across a test candidate that is available for flow modulation.

TABLE I.-FLOW CONDITIONS GERMANE TO NASA'S INITIAL ACTIVE COMBUSTION CONTROL RESEARCH

\begin{tabular}{|c|c|c|}
\hline $\begin{array}{c}\text { Flow number, } \\
\left.\text { FN (pph. } \mathrm{psi}^{-0.5}\right)\end{array}$ & $\begin{array}{c}\text { Mass flow rate, } \\
\dot{m}(\mathrm{pph})\end{array}$ & $\begin{array}{c}\text { Combustion pressure, } \\
\text { P4 (psig) }\end{array}$ \\
\hline 110 & 500 & 200 \\
110 & 375 & 200 \\
110 & 250 & 200 \\
\hline
\end{tabular}

The pressures being dealt with here required certain safety considerations. All components and plumbing used in the rig's construction were required to comply with a pressure rating of at least 1.5 times the working pressure, and they were also required to be compatible with either city water or jet fuel as a working fluid. For simplicity, city water is currently used as the working fluid. Water exiting the rig is routed to drains rather than recirculated to avoid possible contamination with entrained air which changes the compressibility of the working fluid. Should jet fuel be used in the future, the fuel would be routed back to a point in a large reservoir far removed from the inlet to the rig. 


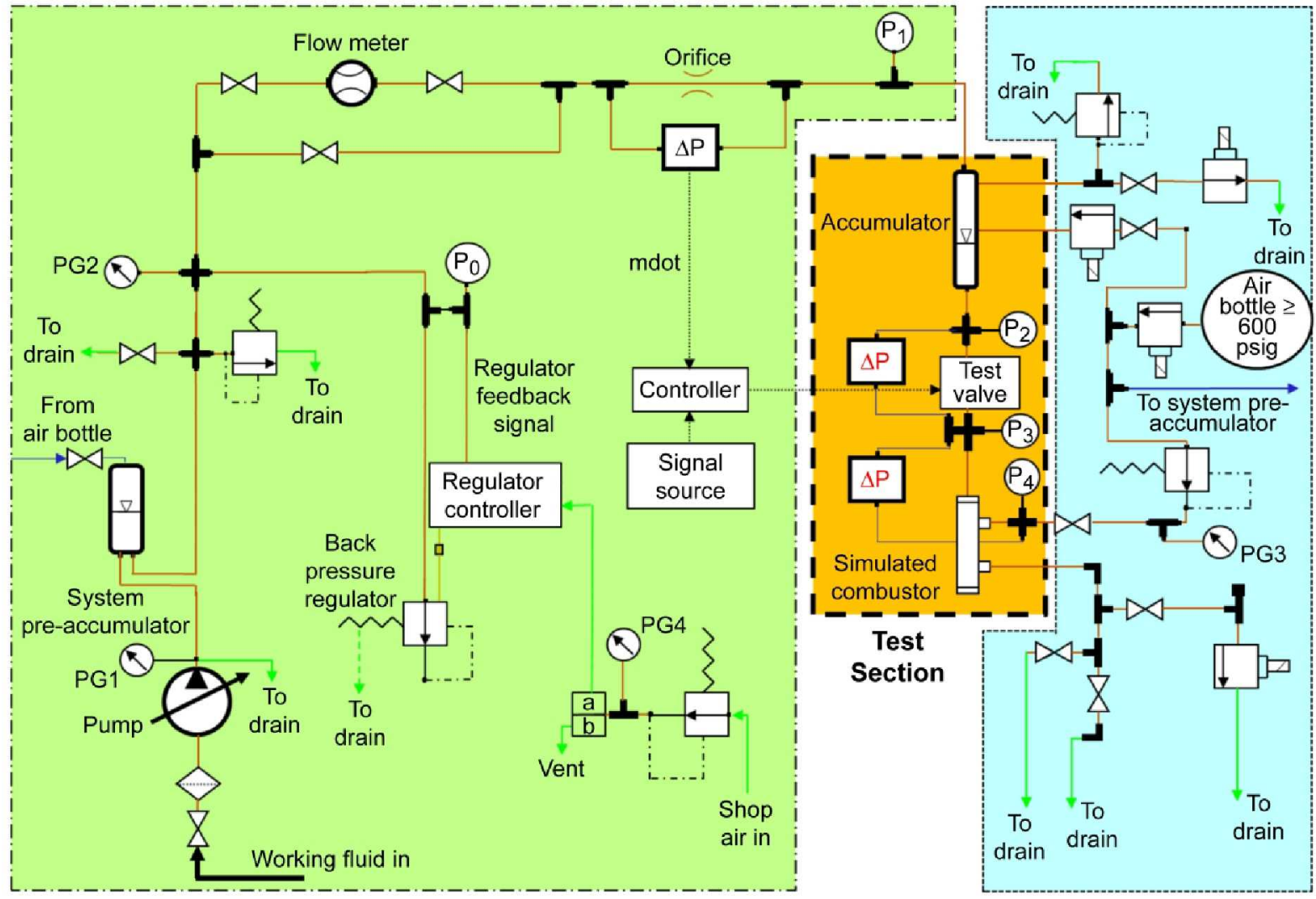

Figure 1.- Schematic of the NASA Glenn high bandwidth valve characterization rig.

A schematic of the characterization rig's overall construction can be seen in Figure 1. The schematic highlights three distinct functional groups labeled Fluid Supply System, Test Section, and Ancillary System. The Fluid Supply System components upstream of the Test Section are responsible for preconditioning and measuring the fluid supply. The Ancillary System components adjacent to and downstream of the Test Section provide pressurization and evacuation support. These three functional groups will be described in more detail in the following sections with emphasis placed on the Test Section. Rig instrumentation will be described in more detail in a separate Instrumentation section of this paper.

\section{Fluid Supply System}

The Fluid Supply System employs a CAT (CAT Pumps Corp.) positive displacement piston pump for delivering the working fluid to the Test Section. It is rated for $2 \mathrm{gpm}$ delivery at $2000 \mathrm{psi}$. The system receives input from the city water supply at a steady pressure between 40 and $75 \mathrm{psig}$. Given the nature of this type of pump, the discharge pressure signal is quite noisy. The exact magnitude of the noise level has never been quantified, but it is considered significant as it adversely affects flow measurements taken a short distance downstream of the pump. To reduce this noise and to better condition the fluid input to the Test Section, a pre-system accumulator is employed. The accumulator used for this purpose is of in-house construction. It is a vertically oriented 1-in. inner diameter (i.d.) stainless steel tube with inlet and outlet fittings for the working fluid installed at the bottom. Inside the tube, the column of fluid is in contact with a volume of air occupying the top of the tube due to natural buoyancy. The volume of air is manually controlled by a valve connected to a pressurized air source. The volume of air inside the tube acts as an adjustable damper and attenuates pressure disturbances in the fluid. The quieted working fluid flow exiting the tube is then acted upon by a computer-controlled back pressure regulator located a short distance downstream. This device establishes the system pressure associated with a specified flow 
condition for which testing will be performed. The device used for this purpose is a (computer) voltagecontrolled Tescom (Tescom Corp.) regulator mounted to a Tescom backpressure regulator. The maximum inlet pressure to the backpressure regulator is $10000 \mathrm{psig}$ which enables the working fluid control range to vary from 10 to $1500 \mathrm{psig}$. Since the pump can output a pressure of $2000 \mathrm{psig}$ and the system is rated at $900 \mathrm{psig}$, a safety relief valve set to $700 \mathrm{psig}$ allows some margin around the maximum working pressure of 600 psig. An Entran (Entran Devices, Inc.) EPXO absolute pressure transducer (labeled P0) rated at 1000 psia full scale with frequency response of $19 \mathrm{kHz}$ is used to provide feedback to the regulator's electronic control. The feedback allows the regulator to maintain a user-defined system pressure. The pressure setting is arrived at iteratively by the rig operator as the specified flow condition is established for testing. The flow measurements from both a turbine-type flow meter and an orifice/differential pressure transducer supply feedback to the operator. The turbine-type flow meter is used for supplying a time-averaged measure of the flow and the orifice/pressure transducer system provides (relative to the turbine meter's time-averaged measurement) an instantaneous measure of the flow. These are discussed further in the Static and Dynamic Instrumentation sections of this paper.

\section{Test Section}

The Test Section, shown in Figure 2, is the heart of the characterization rig. It is comprised of three main components which are: 1) a second accumulator to smooth the flow into the flow modulator test candidate; 2) the test candidate; and 3) a vessel designed to permit the simulation of modulated fuel into a

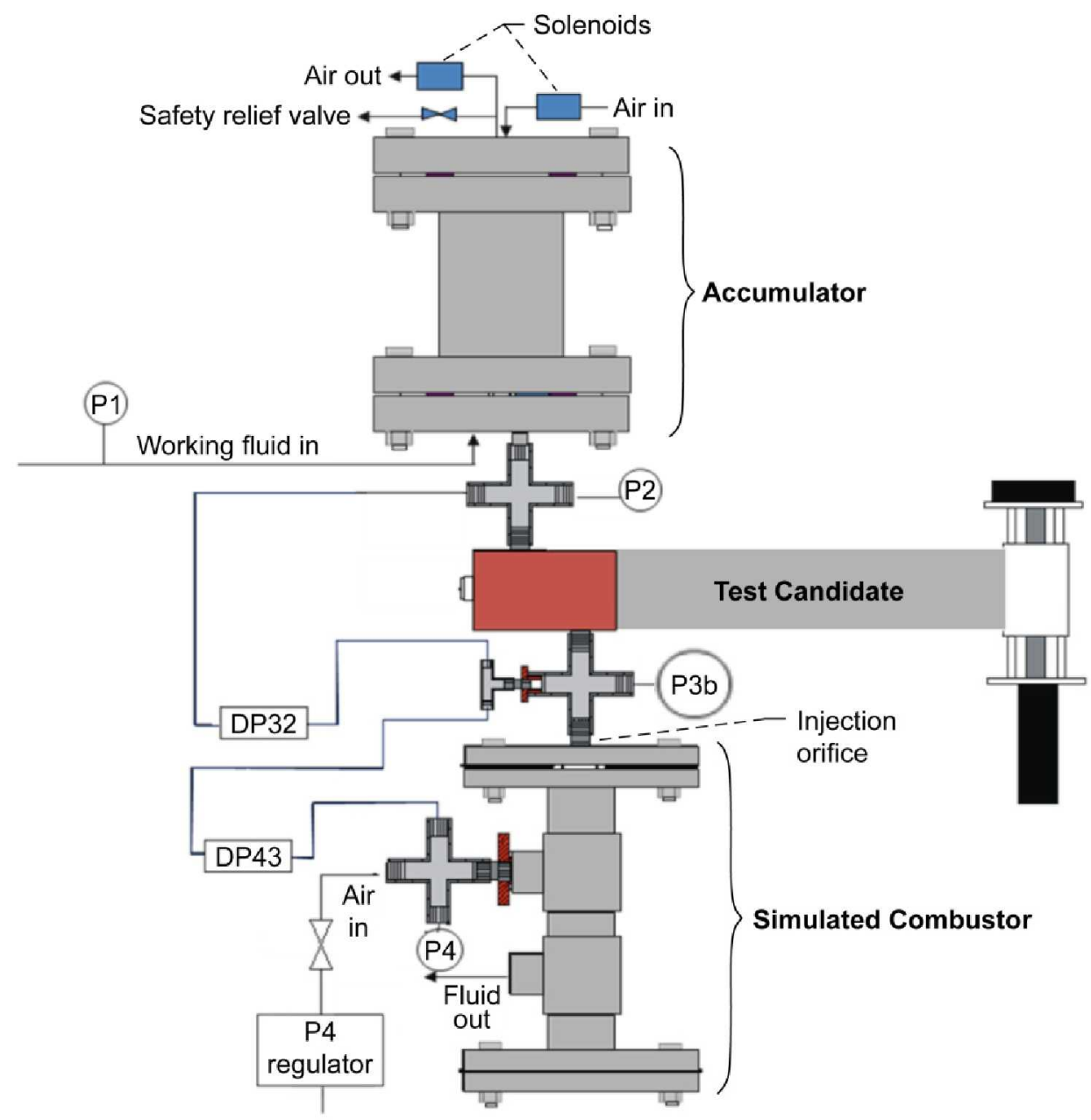

Figure 2.-The Test Section (shown for the "short" configuration) comprised of the Accumulator, the Test Candidate, and the Simulated Combustor. 
combustion rig under cold flow conditions. The accumulator and the "Simulated Combustor" will be described in detail in the paragraphs that follow. The test candidate is discussed in generic terms due to the variances that exist among the different designs. The Test Section components will be described while making reference to the components that comprise the Ancillary System that provides support to the Test Section.

\section{Accumulator}

The accumulator is a pressure vessel of in-house design and construction. A cut-away drawing can be seen in Figure 3. It is constructed with 304 stainless steel, $300 \mathrm{lb}$ threaded and blind flanges, and it uses a 6-in. long, 3-in. i.d., 304 stainless steel seamless pipe nipple. The bottom blind flange was drilled through in two locations to permit the installation of fittings that accept the fluid inlet and outlet lines. Above the inlet fitting, on the surface of the blind flange internal to the accumulator, a welded flow baffle was installed. Its purpose is to isolate the turbulent incoming flow from the area around the accumulator's exit. The top blind flange is also modified. It has two sets of double holes drilled through the flange. One set of holes permit the attachment of a pair of 1/8 in. stainless steel pipe nipples that are staggered in length. These nipples serve as attachment points for float switches. The switches thread onto the nipples and the wires from the switches travel inside the nipples to exit the accumulator. The wires are connected to a relay logic board that provides independent control of solenoid valves responsible for either venting pressure from the accumulator or for introducing regulated compressed air. The second set of holes permit the attachment of fittings for the vent line and the incoming compressed air. Normally open (N.O.) solenoid valves are placed in-line for each of those respective pathways with the inclusion of a safety relief valve (set at $625 \mathrm{psig}$ ) on the vent line to prevent a possible over-pressure situation. The normal operation of the accumulator is to have fluid enter from the bottom and rise upward into the vessel. The

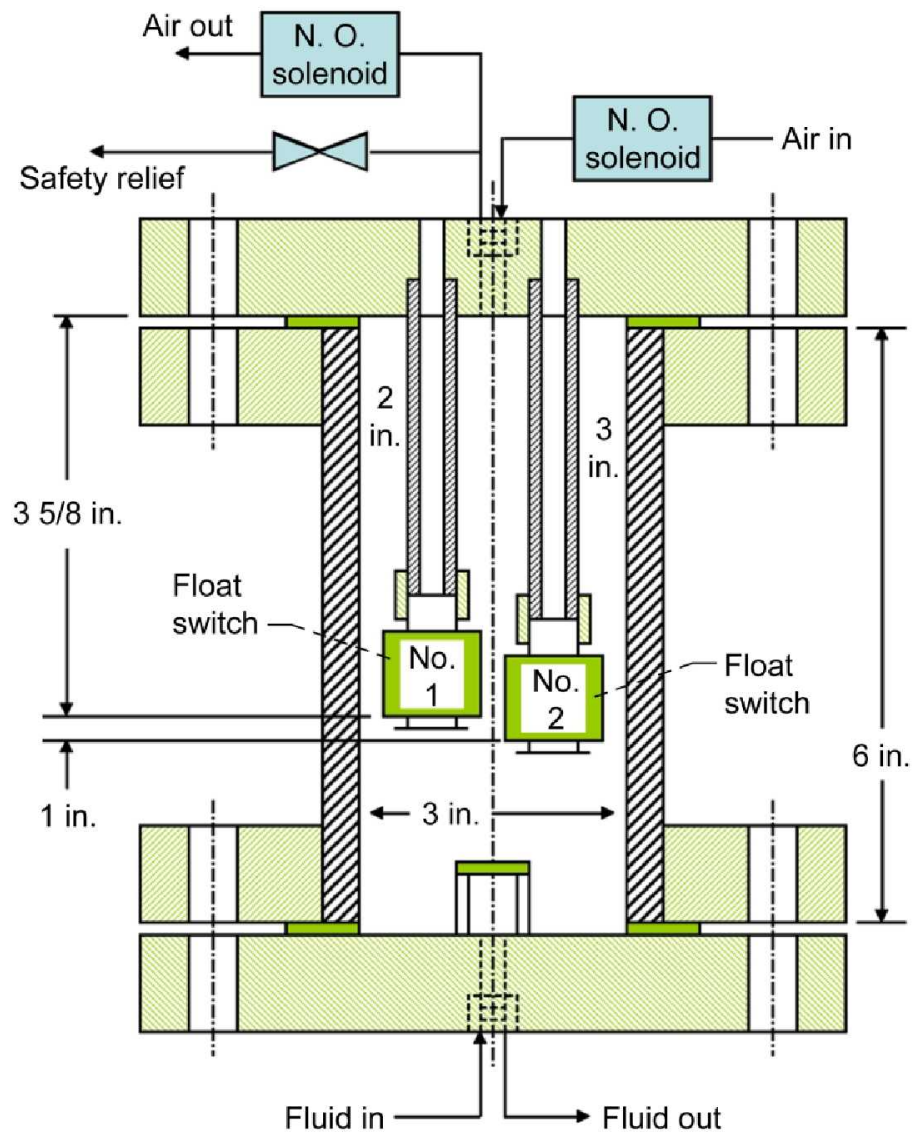

Figure 3.-The Accumulator. 
float switches are both normally open, so for this state the vent pathway is open while the incoming compressed air pathway is kept closed. As the fluid level rises, switch no. 2 floats upward and closes. If switch no. 1 remains open the vent pathway closes. This is the desired state for the accumulator. Should the fluid level continue to rise and cause switch no. 1 to close, the solenoid controlling the incoming compressed air pathway energizes and permits compressed air (regulated at a pressure greater than the fluid working pressure, but less than $625 \mathrm{psig}$ ) to enter. The air pushes the fluid column downward sufficiently for switch no. 1 to open, at which point, the incoming air pathway closes. In contrast to conventional pre-charged accumulators, this accumulator with its air control system maintains a fixed air volume so that the compliance stays constant regardless of the operating pressure. In practice, if the flows and pressures are balanced in the rig, the control system described here activates only rarely.

A measure of merit for the performance of the accumulator is the comparison of absolute pressure measurements taken immediately upstream of the accumulator (P1) and immediately downstream of the accumulator (P2). A representative plot of this comparison is shown in Figure 4. As can be seen in the figure, the accumulator is very effective in buffering relatively high power, high frequency flow content to a much lower power, lower frequency flow. The resulting pressure has an amplitude of $\pm 1 \mathrm{psig}$.

However, since this design has a direct air-fluid interface, questions arise as to whether the air can find its way into the fluid exiting the bottom of the accumulator thereby posing a potential loss of performance by the test candidate due to the introduced compressibility. A quantified measure of the potential impact from this condition remains a research issue.
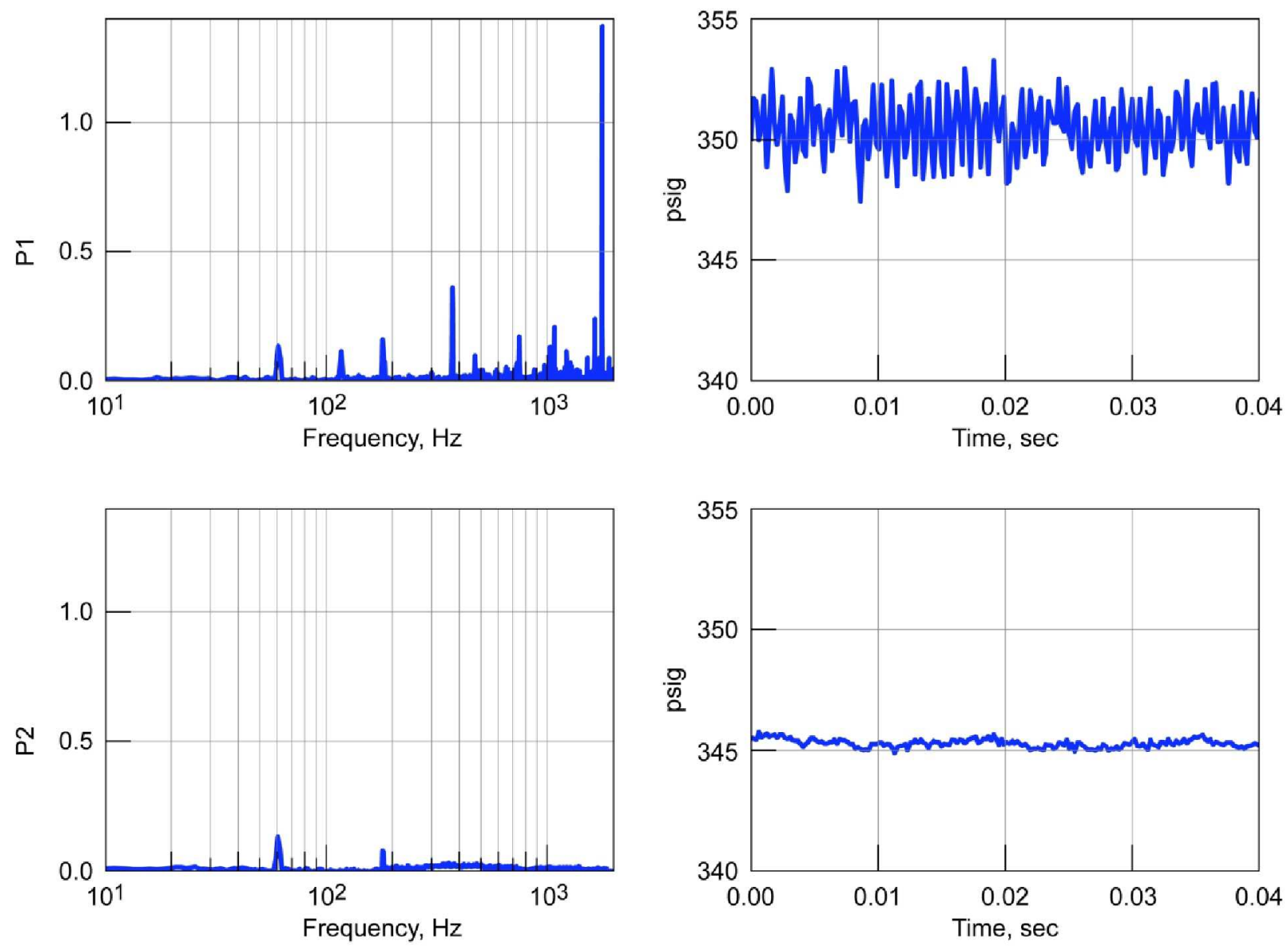

Figure 4.-Comparison of pressure measurements upstream and downstream of the accumulator. 


\section{Test Candidate}

The test candidate is installed in the rig such that the physical connection length between the accumulator's exit and the test candidate's input is minimized. The length, however, must also accommodate a connection point for both an absolute pressure transducer (P2) and for the upstream input of a differential pressure transducer, DP32, that measures across the test candidate. At the test candidate's discharge location, a provision must be made to permit the installation of an absolute pressure transducer (P3x), connections for the downstream input of the differential pressure transducer DP32, and for the upstream input of the differential pressure transducer DP43. These pressure transducers are used to measure performance during modulation and provide feedback to the rig operator during the establishment of the testing flow conditions.

\section{Simulated Combustor}

The final component associated with the Test Section is the "Simulated Combustor". This pressure vessel is also of NASA design and fabrication. A cut-away drawing of its construction can be seen in Figure 5. The purpose of this component is to provide simulated injection and back pressure conditions for the test candidate similar to those experienced as if it were actually feeding a combustor (sans high temperature exposure). The construction of the vessel uses 304 stainless steel, $300 \mathrm{lb}$ blind and threaded flanges, 1 in. i.d. stainless steel schedule 40 seamless pipe nipples, 304 stainless steel class 3000 psi 1 -in. pipe tees, and 304 stainless steel class 3000 psi 1-in. by 1/8-in. bushings.

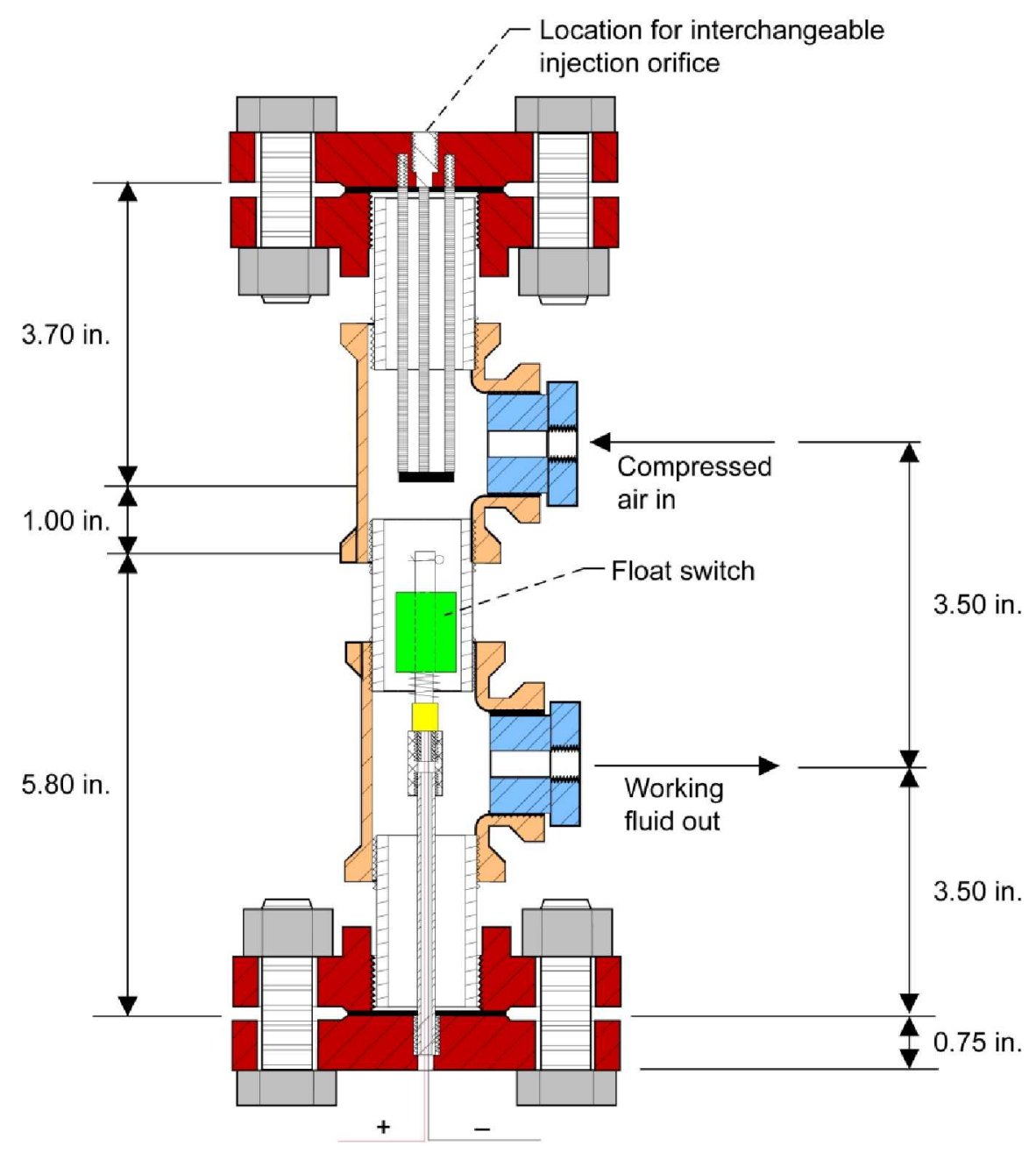

Figure 5.-The Simulated Combustor. 
The upper blind flange of the vessel was machined to permit the installation of a $1 / 8$-in. NPT (by 3/4-in. length) pipe nipple that has been modified to include a press-fit ruby insert having a precisely drilled orifice. These orifices are manufactured by Bird Precision (Bird Precision). The manufacturer offers a range of orifice diameters that permit interchangeability in the size of the orifice being used. This facilitates the ability to change flow number to simulate different sized fuel injectors. The nipple also serves as the connection point to the test candidate. As shown in Figure 2, the physical distance between the test candidate and the orifice is minimized. This has been frequently referred to as the "short" configuration. One would expect the measured performance of the candidate to be best for this configuration. In reality, gas turbine engine combustors and the research combustion rigs that emulate them require the connection for the fuel supply be made externally. Typically a length of tubing (minimally 12 in. and up to 36 in.) travels internally from the connection point to the fuel injector location. For a modulated fuel supply this could impose losses. For this reason, the characterization rig permits the insertion of a length of tubing between the test candidate and the orifice. The 1,2 , and $3 \mathrm{ft}$ lengths have been used for this purpose. Custom lengths can also be inserted to emulate a particular installation. If an extended configuration is employed, absolute pressure transducers are used at the candidate's discharge ( $\mathrm{P} 3 \mathrm{a})$ and at the termination of the tube length near the orifice $(\mathrm{P} 3 \mathrm{~b})$. This is referred to as the "long" configuration. Differential pressure transducer, DP43, is intended to measure across the flow orifice, so its upstream connection point will be made nearest the entrance to the orifice regardless of the configuration.

The remainder of the components that comprise the Simulated Combustor form a pressure vessel having two bosses. The upper boss provides a port through which compressed air can be introduced thereby creating the simulated back-pressured combustor environment. Fluid passing through the orifice enters the pressurized vessel and accumulates at the bottom. A second boss in the vicinity of the vessel's bottom provides the exit to a drain or reservoir at atmospheric conditions. The desired height of the water column inside the vessel is a distance approximately equivalent to half its length. This is to ensure a pressurized compartment within the vessel always exists. A float switch, attached to the bottom blind flange, is used to aid in this task. Unlike the automated control used with the Accumulator, an indicator light conveying information on the state of the float switch is used by the rig operator to adjust needle valves that control the rate of fluid exit from the vessel. An iterative process is employed to achieve a steady-state condition for the desired water column height. There is some automation employed, however. Should the primary flow path back to the reservoir be too restrictive, the liquid level will rise thereby causing the float switch to close. This will cause a normally open solenoid on one of the exit paths to energize, thereby making this secondary flow path available to the flow as a return to the drain/reservoir. To guard the float switch from the incoming fluid, a disruptor plate is suspended above the switch by three stainless steel rods that are attached to the upper blind flange.

\section{Ancillary System}

The Ancillary System adjacent to the Test Section provides the compressed air and its regulation for the Accumulator and the Simulated Combustor. A bottle of compressed air with a maximum capacity of $2000 \mathrm{psig}$ is located a remote distance from the characterization rig. The primary flow from the bottle is regulated to a value slightly greater than the working pressure that is to be used for a given test. This pressure is bounded by $600 \mathrm{psig}$, the maximum working pressure permitted. A normally closed solenoid valve acts as a barrier to the entrance of the characterization rig plumbing. When the rig is not being used, the solenoid prevents the rig from being accidentally pressurized. When the rig is to be used for testing, an operator must energize the solenoid to permit the air flow. The primary regulated air supply is then made available to the Accumulator. For the Simulated Combustor, the primary regulated supply is further regulated, supplying the backpressure to that vessel which typically does not exceed 300 psig. 


\section{Instrumentation and Data Acquisition}

In order to fully characterize the behavior of a fuel valve test article, two classes of instrumentation are employed. First, static measurements are used to document the steady operating condition of the rig and the corresponding steady flow conditions through the valve under test. Second, dynamic measurements are used to document the unsteady flow behavior resulting from time-varying commands being supplied to the valve.

\section{Static Instrumentation}

The list of static instrumentation is shown in Table II. Three main parameters are monitored and also recorded with the research data in order to document the overall operating conditions of the rig. The rig inlet pressure PG2 (pump outlet pressure, see Fig. 1) is set by a pressure regulator, as described in the previous section, and monitored by a pressure gauge. The rig inlet pressure is also recorded with the dynamic data (see below). The Simulated Combustor control pressure PG3 (rig outlet pressure, see Fig. 1) is controlled by a pressure regulator and by the exit valves of the rig, and is monitored by a second pressure gauge. The resulting fluid flow, Wf, is a product of the delta pressure drop across the rig and the various flow restrictions within the rig (including the valve) and is monitored by a turbine flow meter and associated flow monitor. A Blancett (Blancett) model 1225 turbine flowmeter and associated model B2400 flow monitor are used. The flow meter is modular and can be interchanged with different models to accommodate different flow ranges. The flow monitor is programmable with configurable linearization (K-Factor) breakpoints. A front panel display provides a readout in the engineering units of choice, and a 0 to $10 \mathrm{~V}$ output proportional to volumetric flow is provided for recording with the data system. The flow monitor outputs (display and voltage output) are both updated once a second.

TABLE II.-STATIC INSTRUMENTATION

\begin{tabular}{|l|l|l|}
\hline \multicolumn{1}{|c|}{ Name } & \multicolumn{1}{|c|}{ Description } & \multicolumn{1}{c|}{ Sensor employed } \\
\hline PG2 & Rig inlet pressure & Pressure gauge \\
\hline Wf & Mean fluid flow & Flow meter and associated flow monitor \\
\hline PG3 & Simulated combustor control pressure & Pressure gauge \\
\hline TCdegF & Fluid temperature & Type K thermocouple \\
\hline
\end{tabular}

A thermocouple to sense fluid temperature is optionally available. This was primarily used when the rig was recirculating fluid to monitor the fluid temperature rise generated by the pump. It is not currently installed in the rig.

\section{Dynamic Instrumentation}

The list of dynamic instrumentation is shown in Table III. There are five (optionally six) dynamic pressure sensors along the flow path of the rig (P0 to $\mathrm{P} 4$ ). The locations of the dynamic pressure sensors are shown in Figures 1 and 2. All of these use an Entran EPXO 1000 psia transducer. The sensors have a natural frequency of $95 \mathrm{kHz}$ and are easily able to capture the up to $2 \mathrm{kHz}$ phenomena from valve characterization. Each transducer is mounted in a pipe-tee fixture that has been machined to place the face of the sensor flush with the flow passage side wall. This is done to obtain maximum sensitivity and to minimize flow disturbances in the vicinity of the sensor. For short feed line configurations, where the distance between the valve and the simulated fuel injector is less than 6 in., only one P3 sensor is used ( $\mathrm{P} 3 \mathrm{~b}$ - the injector inlet pressure). When the feed line is greater than $6 \mathrm{in}$. long, two P3 sensors are used (P3a, P3b) in order to measure any acoustic phenomena in the feed line. 
TABLE III.-DYNAMIC INSTRUMENTATION

\begin{tabular}{|l|l|l|}
\hline \multicolumn{1}{|c|}{ Name } & \multicolumn{1}{|c|}{ Description } & \multicolumn{1}{c|}{ Sensor employed } \\
\hline P0 & Rig inlet pressure & Entran EPXO series \\
\hline P1 & Accumulator inlet pressure & Entran EPXO series \\
\hline P2 & Accumulator outlet/valve inlet pressure & Entran EPXO series \\
\hline P3a & Valve outlet pressure & Entran EPXO series \\
\hline P3b & Simulated injector inlet pressure & Entran EPXO series \\
\hline P4 & Simulated combustor pressure & Entran EPXO series \\
\hline DP32 & Valve delta pressure & Druck PMP 4165 series \\
\hline DP43 & Simulated injector delta pressure & Druck PMP 4165 series \\
\hline FLOW & Fluctuating fluid flow & Orifice and Sensotec differential pressure \\
\hline
\end{tabular}

To infer dynamic mass flow, differential pressure sensors are used. Sensor DP32 measures the differential pressure across the test article (between locations P2 and P3a or P3b). Sensor DP43 measures the differential pressure across the simulated injector (between locations P3b and P4). These measurements use Druck PMP4165 transducers. The transducer across the valve has a range of 50 psid and the transducer across the simulated injector has a range of $500 \mathrm{psid}$. Transducers with different ranges can be employed if the range of pressure drop across the valve and/or simulated injector changes due to valve or injector cross-sectional area changes. The Druck differential pressure transducers do not have a published spec for natural frequency, but experience has shown them to be more than adequate for measuring the up to $2 \mathrm{kHz}$ valve induced perturbations. The time-varying mass flow across the simulated injector, as inferred from DP43, is intended as the figure of merit for fuel modulator effectiveness.

Fluctuating fluid flow is measured using an orifice with a Sensotec (Honeywell (Sensotec))Model Z transducer measuring the differential pressure across the orifice. The orifice and the differential pressure transducer combination is modular and can be interchanged to allow for different flow ranges. This measurement is upstream of the accumulator and is not intended to be an indication of the fluid flow fluctuations caused by the flow modulator under test. Rather, it is used to set the mean flow through the flow modulator (the DC position) about which the modulation occurs. The mean value for this flow measurement and the steady flow measured by the flowmeter (see previous section) should agree, although the orifice/differential-pressure measurement gives a higher response measurement.

\section{Signal Conditioning and Data Acquisition}

Endevco (Endevco Corp.) 4430A signal-conditioner/filter/amplifier modules supply the excitation voltage and bridge completion for the Entran and Druck transducers. In addition, all electronic measurements (not pressure gauges) are amplified as necessary and low-pass filtered for anti-aliasing using the Endevco 4430A's. The steady and low-frequency dynamic measurements have a low pass cut-off frequency set at $25 \mathrm{~Hz}$ and are sampled at $50 \mathrm{~Hz}$. The high-frequency dynamic measurement cut-off is $2 \mathrm{kHz}$ while sampled at $5 \mathrm{kHz}$. A dSpace (dSpace, Inc.) real time processor system based on the DS1005 PowerPC processor board is used for data acquisition and control. A DS2003 32-Channel Analog-toDigital board with simultaneous sample-and-hold is used for voltage inputs. A DS2102 6-Channel Digital-to-Analog board is used for outputs. All voltage inputs/outputs are $\pm 10 \mathrm{~V}$. Data is recorded and saved to Matlab (The MathWorks) .mat files for post-processing.

\section{Testing Procedure}

Each test begins with a calibration check of the pressure transducers. The offset of each transducer is checked at ambient pressure conditions, i.e., no system flow. The rig is then pressurized with compressed air to 200 psig to verify transducer span. At the completion of testing, each transducer calibration is once again checked at ambient conditions. After the transducer calibration check is performed, the pump is activated and steps are taken to establish the flow condition for testing. These steps include setting the rig inlet pressure, the Simulated Combustor control pressure, the steady position of the flow modulator, and the flow outlet valves. Once test conditions are established, data is taken to document the steady-state 
condition. The steady-state flow for this established condition is what must be maintained through the test candidate (in a time-averaged sense) during its modulation. As will be mentioned below, some candidates incorporate their own control system to maintain this mean flow. For these flow modulators, the procedure is to then engage the test candidate's mean flow controller. Once engaged, data is taken to document this condition.

With the flow condition established and the mean flow controller activated, the ensuing procedures are directed at collecting performance data on the test candidate. Data from two types of testing are sought. The first type of testing subjects the test candidate to sinusoidal commands. The commands are issued at discrete frequencies and progress in frequency increments of $100 \mathrm{~Hz}$, spanning the range of 100 to $1500 \mathrm{~Hz}$. The frequencies are traversed in a "forward" (increasing) direction and in the "reverse" (decreasing) direction to provide repeat data and to check for the presence of any hysteresis. At each test frequency the test candidate is allowed to operate until it is apparent that the system has reached an equilibrium condition. Five seconds of data are then recorded. As mentioned in the previous section, two separate data sampling rates are used. High frequency parameters having to do with flow modulator response are recorded at $5 \mathrm{kHz}$ while low frequency parameters having to do with rig conditions are recorded at $50 \mathrm{~Hz}$.

After the discrete frequency data is collected for the specified range in both the forward and reverse directions, the second type of testing is performed. This entails subjecting the candidate to a sinusoidal frequency sweep (performed with a logarithmically-increasing frequency vs. time), spanning the same frequency range used for the discrete sampling. The purpose for conducting the sweep is to permit the generation of a transfer function that can be used to evaluate the test candidate on the basis of frequency response.

\section{Test Results}

The ultimate goal for a high bandwidth fuel modulation device is to supply a modulated fuel pulse into a combustor so as to influence the time-varying pressure waves generated in the combustion process. The frequency of the modulated pulse is in response to a command from a controller that receives feedback information about the combustion instability, typically via frequency and phase of the timevarying pressure. In the ideal case the modulated fuel pulse should possess the appropriate frequency (without introducing others) and it should be of sufficient amplitude to cause an influence in the combustion process. Given the current, qualitative expectations for the modulation device, metrics can none-the-less be defined to evaluate a candidate's performance. In general terms, the metrics would thus include frequency response and modulation strength. The frequency response would ideally be flat over a bandwidth of $1 \mathrm{kHz}$ (higher than most currently observed gas-turbine combustion instabilities) and modulation strength would be defined subjectively to be \pm 40 percent of the mean fuel pressure (as large or larger than that required for most current combustion instability control applications). These requirements are currently subjective since the quantity of fuel to cause this influence (or to what degree) is not exactly known and is highly configuration dependent. It is expected that more quantitative specifications can be developed as experience is gained using such modulation devices with combustors, and as models of the physical processes associated with combustion instability improve.

The assessment of a candidate's performance is made through an evaluation of time-averaged data, frequency response plots, spectral analysis, and time history data. The available number of measured or calculated quantities can be numerous, but in general there is a standard set of quantities that are examined for each test performed. This standard set will be shown here. They include pressures P1, P2, P3b, P4, DP32, and DP43; and the candidate's input command RefA.

The test results being shown here are meant to be demonstrative. It is not the intent of the authors to draw any conclusions about a particular candidate tested in the past. The purpose here is to simply show an example of typical post-processed results stemming from the characterization testing. It is, however, useful to know the generic makeup of the test candidate that is responsible for the results that will be shown. In general terms, the candidate was a valve that uses magneto-strictive actuation. It was designed 
to accept an input supply at $600 \mathrm{psig}$ and to provide modulation up to at least $1000 \mathrm{~Hz}$. It was also designed to provide a maximum output of $500 \mathrm{pph}$, with a maximum pressure drop of $300 \mathrm{psi}$. This candidate was also designed with custom electronics that included a controller to maintain the mean flow while modulating the working fluid. As mentioned previously, the initial testing conditions for NASA's combustion control research, and thus the initial design focus on the characterization rig, was on main injectors with a Flow Number of 110 and fuel flow of up to $500 \mathrm{pph}$. The test candidate was originally designed and utilized for testing at those conditions, although it was not fully characterized there. More recent research has focused on the modulation of the combustor's pilot flow. For this situation flow conditions more appropriate to a Flow Number of 8 to 10 are in order. Thus, the data that will be shown resulted from tests that required the candidate to modulate flow through an injection orifice having a Flow Number of 8 to 10 and a mean flow of about $90 \mathrm{pph}$.

The plot shown in Figure 6 is of time-averaged data. This type of data is used to determine the confidence associated with the collected data, and it also serves to validate the proper operation of the test candidate's mean flow controller. This data is generated offline by time-averaging the individual time history data files for the discrete frequency perturbations (in both the forward and reverse traverses of the frequency range). In the ideal case, the pressure measurements should plot as constant values in the timeaveraged sense. Repeated time-averaged values across the frequency spectrum indicate consistent rig conditions during testing. For example, the pressure data depicted in the figure for measurements $\mathrm{P} 2$ and P4 indicate well behaved, repeatable conditions at the entrance and exit of the Test Section. If the data does not so indicate, then there is cause to investigate and to determine whether or not the data may have been tainted.

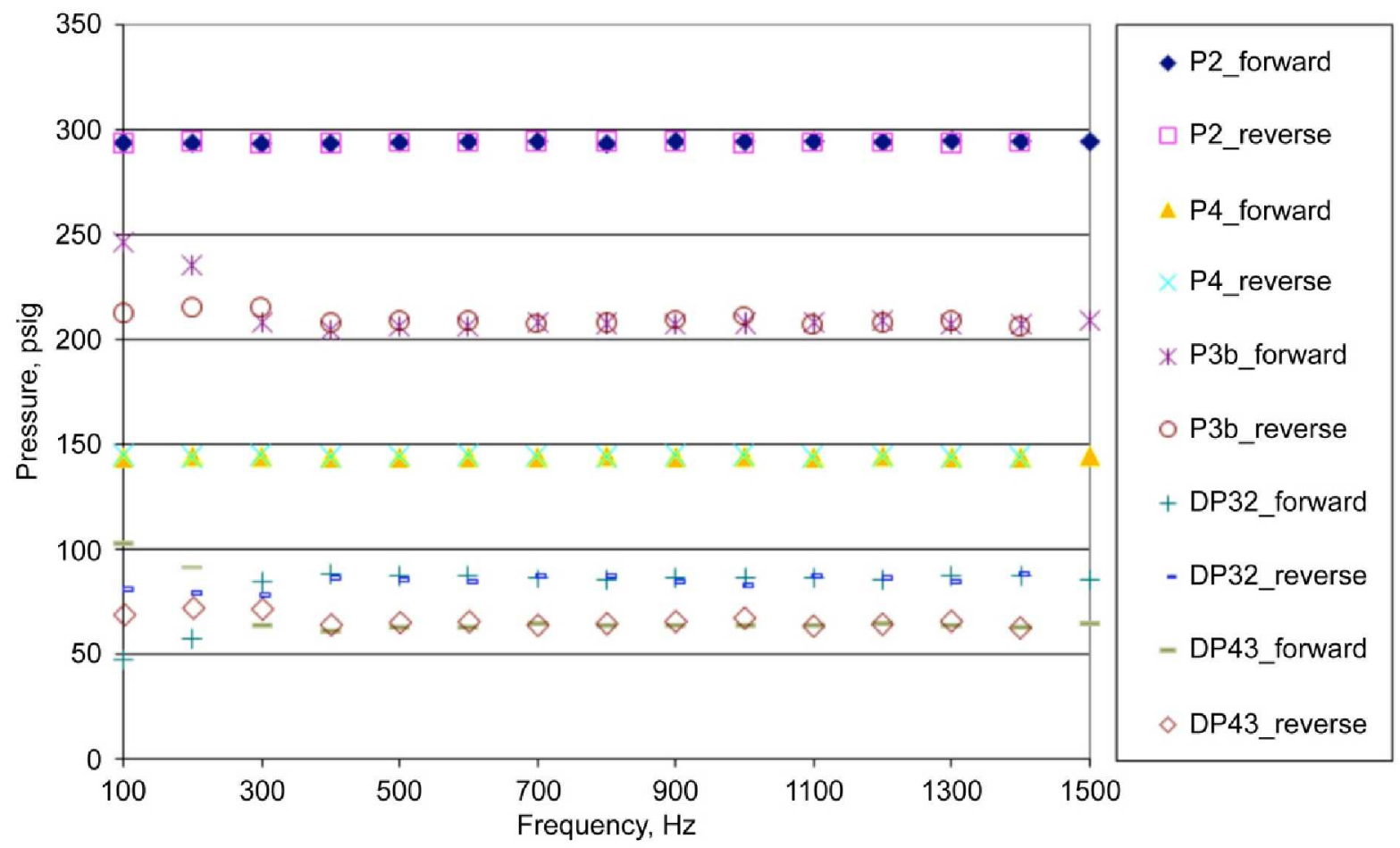

Figure 6.-Time-averaged data for pressure measurements obtained during discrete perturbation testing. 

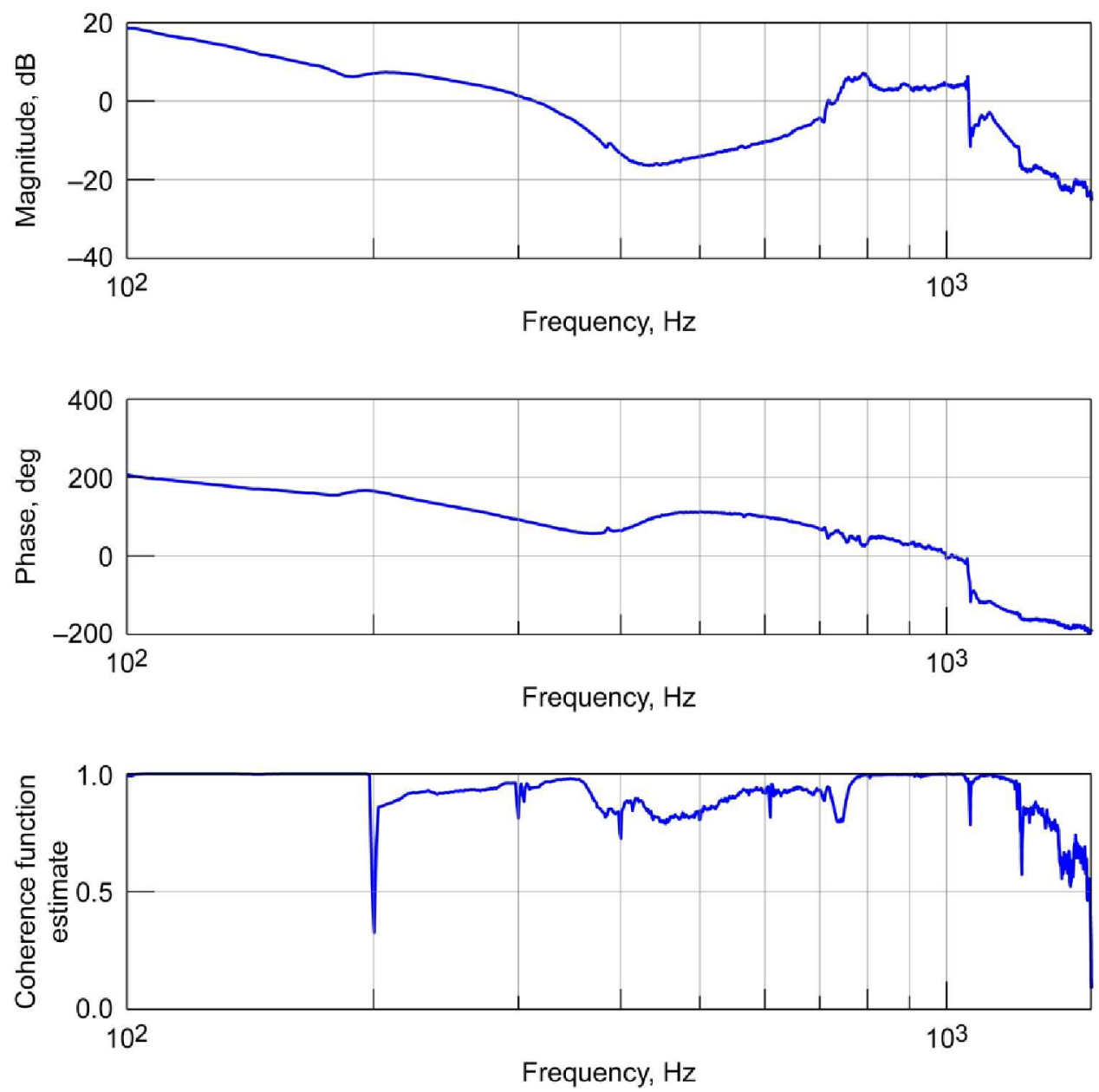

Figure 7.-Frequency response data (DP43/RefA) obtained from frequency sweep testing.

Figure 7 depicts a frequency response assessment of the candidate device using a logarithmic frequency sweep, from 100 to $1500 \mathrm{~Hz}$ over a duration of $80 \mathrm{sec}$. The transfer function shown is defined as DP43/RefA where the output, DP43 (in units of psid), is inferred mass flow through the injection orifice and the input, RefA (in units of volts), is the sinusoidal command input to the candidate. The magnitude and phase plots are presented along with a coherence plot to provide a means of validating the result (the coherence estimate is a value between 0 and 1 that indicates how well the output corresponds to the input at each frequency). These plots do indicate some degradation of the candidate's response as frequency increases. These observations in themselves only provide a qualitative feel for the candidate's ability to perform. To quantify this effect, data is collected at individual frequencies as described next.

As described in the Testing Procedure section, the candidate was perturbed at discrete frequencies from 100 to $1500 \mathrm{~Hz}$. Figure 8 shows time history plots for a subset of the "standard" set of measurements described previously. They are shown with their associated amplitude spectra for the perturbation point taken at $500 \mathrm{~Hz}$. The input command to the valve is depicted in the plot for RefA. It is a sinusoidal signal with an amplitude of $6 \mathrm{vpp}$. The signal was offset from zero to compensate for nonlinearities associated with the displacement of the magneto-strictive material when voltage is applied. The amplitude spectrum indicates a clean signal at $500 \mathrm{~Hz}$ with no "noise" apparent at any other frequency. For the data shown, the candidate provided a clean response as depicted by the data for P3b and DP43, which are indicative of the candidate's output. It is interesting to note that the response of the candidate is not transmitted entirely downstream as evidenced by both the time history and amplitude spectra plots of $\mathrm{P} 2$, the pressure measurement at the input to the test candidate. The energy exhibited in 

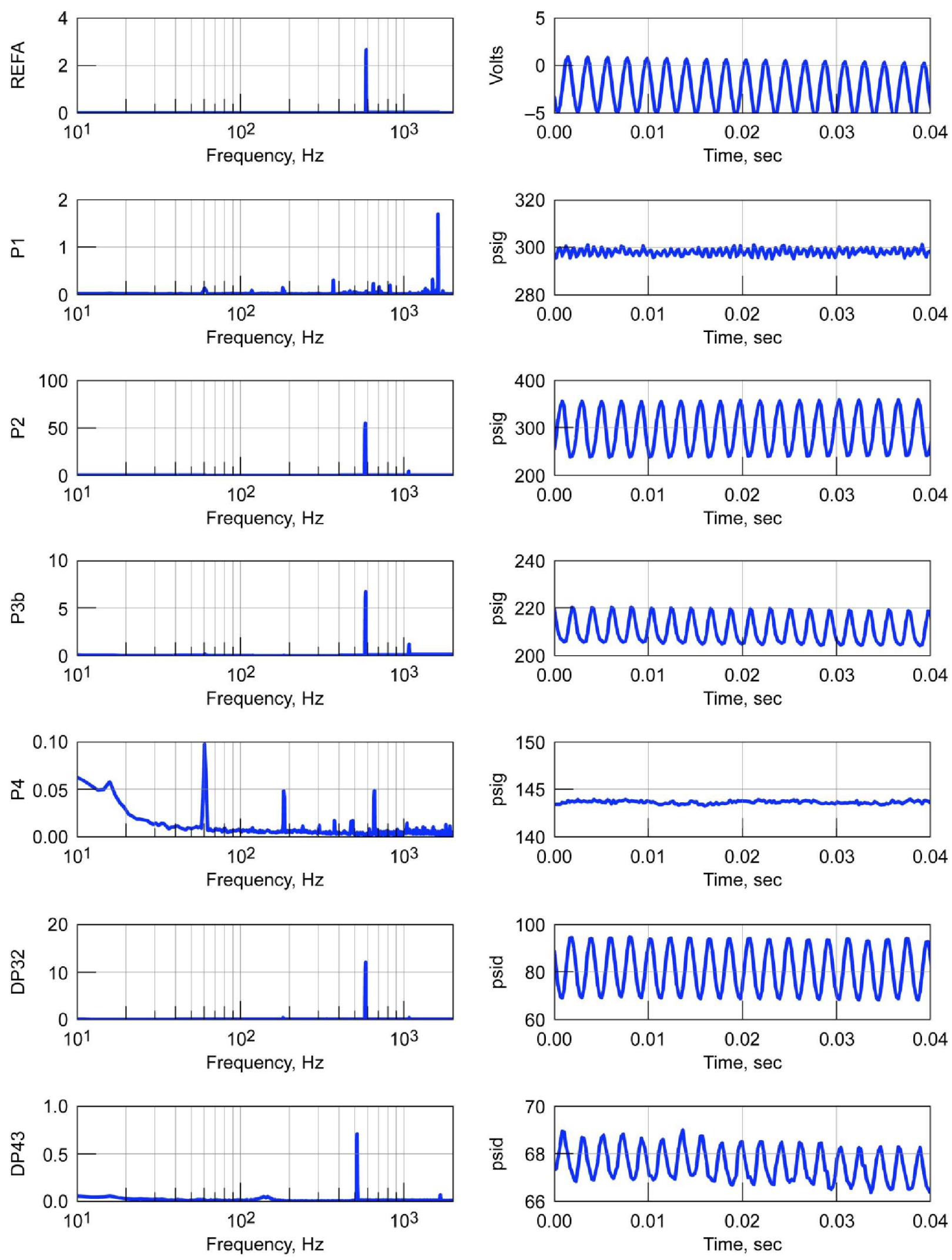

Figure 8.-Fuel modulator spectral analysis and time history data resulting from a perturbation at $500 \mathrm{~Hz}$. 
this signal represents a loss of energy that one would ideally like to see applied to the modulated output. Ideally the measurement for DP43 would be used to assess the candidate's modulation strength. DP43 shows a peak-to-peak modulation strength of about 2 psid. However, the measurement P3b shows a modulation strength of about 15 psi. Since the measurement for P4 is essentially constant these two modulation strengths should be about the same, but that is not the case. The transducer for P3b is mounted with its sensor face flush with the flow (as discussed previously) and it is therefore believed to be more accurate than transducer DP43 which is mounted a short distance from the flow path. The reason for the discrepancy between the magnitude of DP43 and P3b is under investigation. Thus P3b was used as the quantified measure for determining the percent of modulation above and below the mean pressure. For the candidate shown here it was only able to modulate at \pm 5 percent. Since, for these "short" configuration tests, the results did not achieve the desired modulation strength of \pm 40 percent, this particular candidate was not subjected to "long" configuration testing. One possible reason for the small modulation obtained by the candidate is that, while it was designed to modulate flow through a fuel injector with Flow Number of 110, it is being used with an orifice with Flow Number of 8 to 10. Further investigations with this candidate are planned.

\section{Conclusions}

A characterization test rig was designed and developed for evaluating the performance of high bandwidth liquid fuel actuator candidates for active combustion control research. The design goal of the rig was to provide a simulated means by which potential fuel modulation candidates could be tested under conditions that approximated those experienced when installed on a research combustion rig, and ultimately in a gas turbine engine combustor. The characterization rig is capable of using water or jet fuel as the working fluid and it can operate with a maximum working pressure of $600 \mathrm{psig}$. The test section includes a pressurized vessel that simulates the backpressure of a combustor. The rig is instrumented with both pressure and flow transducers and its data acquisition system is capable of real-time data collection and display. Discrete frequency perturbation and frequency sweep testing can be performed. The data collected permits the generation of time-average, time history, amplitude spectra, and bode plots that serve as the basis for actuator performance assessment. Three main metrics are used to evaluate a candidate. They are: 1) actuator bandwidth compliance; 2) working fluid frequency content; and 3) pressure modulation strength about the mean. The rig's design has been documented and preliminary characterization results obtained for one flow modulation device. Future plans are to conduct detailed dynamic characterization studies with multiple flow modulation candidates.

\section{References}

1. Paxson, D.: "A Sectored-One-Dimensional Model for Simulating Combustion Instabilities in Premix Combustors," presented at the 38th Aerospace Sciences Meeting \& Exhibit. AIAA-2000-0313, NASA/TM-1999-209771, January 2000.

2. Cohen, J.M. et al.: "Experimental Replication of an Aeroengine Combustion Instability," International Gas Turbine \& Aeroengine Congress \& Exhibition, Munich, Germany, ASME paper 2000-GT-0093, May 2000.

3. Cannon, S.; Smith, C.; and Lovett, J.: "LES Modeling of Combustion Dynamics in a Liquid-Fueled Flametube Combustor," 36th Joint Propulsion Conference and Exhibit. AIAA-2000-3126, July 2000.

4. Nguyen, Q,: "Measurements of Equivalence Ratio Fluctuations in a Lean Premixed Prevaporized (LPP) Combustor and its Correlation to Combustion Instability," ASME Turbo Expo, Amsterdam, The Netherlands, ASME paper GT-2002-30060, June 2002.

5. Lieuwen, Tim, and Yang, Vigor, Combustion Instabilities in Gas Turbine Engines: Operational Experience, Fundamental Mechanisms, and Modeling, Published by AIAA, (C) 2006, Vol. 210, Progress in Astronautics and Aeronautics Series, 210. 
6. Zinn, B.T.; Neumeier, Y.: "An Overview of Active Control of Combustion Instabilities," AIAA Paper 97-0461, January 1997.

7. McManus, K.R.; Magill, J.C.; Miller, M.F.; Allen, M.G.: “Closed-Loop System for Stability Control In Gas Turbine Combustors," AIAA Paper 97-0463, January 1997.

8. Schadow, K.; Yang, V.; Culick, F.; Rosfjord, T.; Sturgess, G.; Zinn, B.: “Active Combustion Control for Propulsion Systems," AGARD Report 820, September 1997.

9. Murugappan, S.; Aharya, S.; Gutmark, E.; Messina, T.: "Characteristics and Control of Combustion Instabilities in a Swirl-Stabilized Spray Combustor," 35th Joint Propulsion Conference and Exhibit, Los Angeles, CA. AIAA-99-31259, June 1999.

10. Hibshman, J.R.; Cohen, J.M.; Banaszuk, A.; Anderson, T.J.; Alholm, H.A.: "Active Control of Combustion Instability in a Liquid-Fueled Sector Combustor," International Gas Turbine \& Aeroengine Congress and Exhibition, ASME Paper 99-GT-215, June 1999.

11. DeLaat, J.C.; Breisacher, K.J.; Saus, J.R.; Paxson, D.E.: “Active Combustion Control for Aircraft Gas Turbine Engines," 36th Joint Propulsion Conference and Exhibition, Huntsville, AL, AIAA-20003500, NASA/TM-2000-210346, July 2000.

12. Kiel, B.: "Review of Advances in Combustion Control, Actuation, Sensing, Modeling and Related Technologies for Air Breathing Gas Turbines," 39th Aerospace Sciences Meeting and Exhibit, Reno NV, AIAA-2001-0481, January 2001.

13. Johnson, C.; Neumeier, Y.; Neumaier, M.; Zinn, B.; Darling, D.; Sattinger, S.: "Demonstration of Active Control of Combustion Instabilities on a Full-Scale Gas Turbine Combustor," ASME Turbo Expo 2001, New Orleans, LA. ASME Paper 2001-GT-0519, June 2001.

14. Annaswamy, A.M.; Ghoneim, A.F.: "Active Control of Combustion Instability: Theory and Practice," in IEEE Control Systems Magazine, vol. 22, no. 6, pp. 37-54, December 2002.

15. Kopasakis, G.; DeLaat, J.: "Adaptive Instability Suppression Controls in a Liquid-Fueled Combustor," 38th Joint Propulsion Conference and Exhibit, Indianapolis, IN, AIAA-2002-4075, NASA/TM-2002-21805, July 2002.

16. Kopasakis, G.: "High-Frequency Instability Suppression Controls in a Liquid-Fueled Combustor," 39th Joint Propulsion Conference and Exhibit, Huntsville, AL, AIAA-2003-1458, July 2003.

17. Le, D.; DeLaat, J.; Chang, C.: "Control of Thermo-Acoustic Instabilities: The Multi-Scale Extended Kalman Approach," 39th Joint Propulsion Conference and Exhibit, Huntsville, AL, AIAA-20034934, July 2003. 


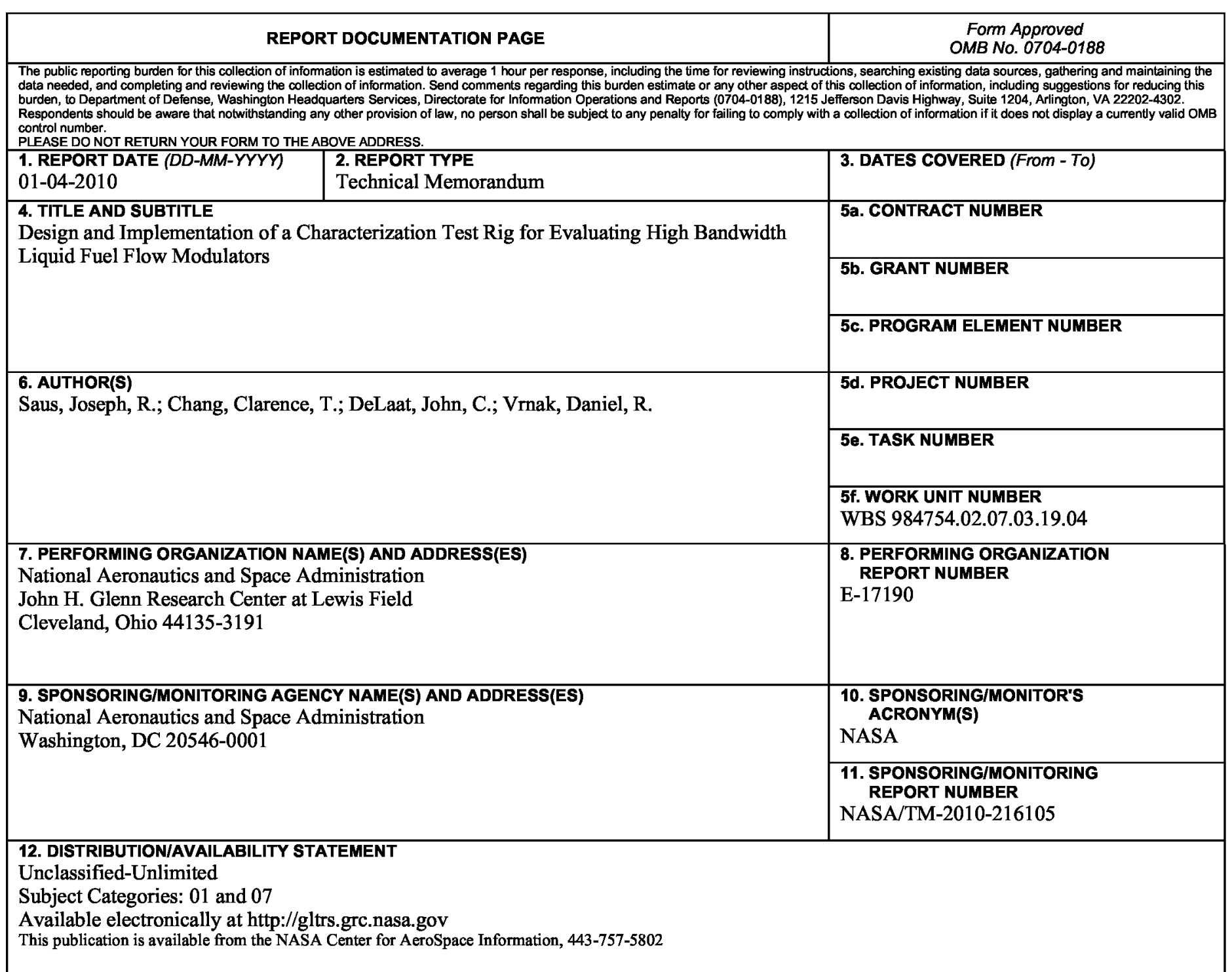

\section{SUPPLEMENTARY NOTES}

\section{ABSTRACT}

A test rig was designed and developed at the NASA Glenn Research Center (GRC) for the purpose of characterizing high bandwidth liquid fuel flow modulator candidates to determine their suitability for combustion instability control research. The test rig is capable of testing flow modulators at up to 600 psia supply pressure and flows of up to $2 \mathrm{gpm}$. The rig is designed to provide a quiescent flow into the test section in order to isolate the dynamic flow modulations produced by the test article. Both the fuel injector orifice downstream of the test article and the combustor are emulated. The effect of fuel delivery line lengths on modulator dynamic performance can be observed and modified to replicate actual fuel delivery systems. For simplicity, water is currently used as the working fluid, although future plans are to use jet fuel. The rig is instrumented for dynamic pressures and flows and a high-speed data system is used for dynamic data acquisition. Preliminary results have been obtained for one candidate flow modulator.

\section{SUBJECT TERMS}

Active control; Combustion stability; Modulators; Liquid fuels

\begin{tabular}{|l|l|l|l|c|l|}
\hline \multicolumn{2}{|l|}{ 16. SECURITY CLASSIFICATION OF: } & $\begin{array}{l}\text { 17. LIMITATION OF } \\
\text { ABSTRACT }\end{array}$ & $\begin{array}{l}\text { 18. NUMBER } \\
\text { OF } \\
\text { PAGES }\end{array}$ & $\begin{array}{l}\text { 19a. NAME OF RESPONSIBLE PERSON } \\
\text { STI Help Desk (email:help@sti.nasa.gov) }\end{array}$ \\
\cline { 1 - 2 } $\begin{array}{l}\text { a. REPORT } \\
\text { U }\end{array}$ & $\begin{array}{l}\text { b. ABSTRACT } \\
\text { U }\end{array}$ & $\begin{array}{l}\text { c. THIS } \\
\text { PAGE } \\
\text { U }\end{array}$ & UU & 22 & $\begin{array}{l}\text { 19b. TELEPHONE NUMBER (include area code) } \\
\text { 443-757-5802 }\end{array}$ \\
\hline
\end{tabular}



